\title{
A role for brown adipose tissue in the genesis of obesity? Studies on experimental animals
}

By P. Trayhurn, Anne E. Goodbody and W. P. T. James, Dunn Nutrition Laboratory, University of Cambridge and Medical Research Council, Milton Road, Cambridge $\mathrm{CB}_{4} \mathrm{I} X \mathfrak{Y}$

Whether or not the processes which constitute thermogenesis play a significant role in the regulation of energy balance has long been a matter of controversy. As some of the other contributors to this symposium will testify the controversy is still far from settled. It is our view, however, that in certain experimental circumstances the evidence in favour of a quantitatively important role for thermogenesis in energy balance is strong, while in others, particularly those relating to man, it is not impressive. The biochemical mechanisms responsible for thermogenesis and their tissue localization have also been matters of considerable uncertainty. Over the years skeletal muscle and the liver have generally been regarded as the most likely sites for adaptive thermogenesis, and a number of mechanisms within these tissues have been proposed. These mechanisms include protein turnover, the $\alpha$-glycerophosphate shuttle, the $\mathrm{Na}^{+}$pump, and various other specific substrate cycles. None of the mechanisms have been widely accepted, however, and this is partly because in many cases, e.g. the fructose-6-phosphate/fructose-I,6-biphosphate cycle, there does not seem to be the potential for generating substantial amounts of heat.

The most recent tissue to receive attention as the main site of adaptive thermogenesis is brown adipose tissue (BAT). Although the importance of this organ to thermoregulatory non-shivering thermogenesis in many new-born and hibernating mammals has been accepted for some time, BAT was considered to be of little significance in the thermogenesis of adult animals (Jansky, 1973). This view has been altered radically in the past 3 years, however, by the results of Foster \& Frydman (1978, 1979). Using radioactively labelled microspheres to determine regional blood flow, together with measurements of arterio-venous differences in oxygen tension across tissues, these authors were able to demonstrate that BAT was the most important site of non-shivering thermogenesis in adult rats (Foster \& Frydman, 1978, 1979). Furthermore, skeletal muscle was shown to play at best only a very minor role.

These results have had considerable impact and changes in the activity of BAT in three different situations relevant to energy balance and obesity have now been demonstrated and are described in this paper.

\section{Mechanism of heat production in $B A T$}

A number of mechanisms for thermogenesis in BAT itself have been postulated, both mitochondrial and extra-mitochondrial. However, the mechanism which has 
gained almost universal acceptance is the proton conductance or leakage pathway described by Nicholls (for a review, see Nicholls, I979). This pathway is, in effect, a mechanism for the controlled uncoupling of mitochondria. In the proton conductance pathway the proton gradient established across the inner mitochondrial membrane by respiration is short-circuited by the passage of the protons back through the membrane via a proton leakage channel. The net effect of this process is that the synthesis of ATP is bypassed and heat generated in its place. The proton conductance pathway can be blocked, and BAT mitochondria consequently recoupled, by purine nucleotides which bind to a specific protein of molecular weight 32000 (Nicholls, 1976; Heaton et al. 1978). The extent to which radioactively labelled purine nucleotides (e.g. GDP) bind to BAT mitochondria has been developed as an index of the 'activity' of the proton conductance pathway, and this has proved to be a valuable experimental tool.

Although the proton conductance pathway is now regarded as the central mechanism for thermogenesis in $\mathrm{BAT}$, other processes may also make some contribution to the total heat generation. These processes include $\mathrm{Na}^{+}$transport across the plasma membrane (Horwitz, 1978) and, in some circumstances, fatty acid turnover (Trayhurn, I98 r).

\section{Genetically obese mice}

The possibility that changes in the activity of BAT may be important to energy balance and obesity was first demonstrated in genetically obese $(o b / o b)$ mice. Although after four weeks of age these animals are hyperphagic (Lin et al. 1977) obesity will still develop when they are restricted to the ad lib. food intake of lean siblings and the early development of the obese syndrome occurs in the absence of hyperphagia (Lin et al. 1977; Rath \& Thenen, 1979; Contaldo et al. 1981). A low energy expenditure is therefore an important-perhaps the key-aetiological feature of obesity in $o b / o b$ mice; this also appears to be true of the diabetic-obese $(d b / d b)$ mouse, and possibly the fatty $(f a / f a)$ rat. In both the $o b / o b$ and $d b / d b$ mutants the low energy expenditure and consequent high metabolic efficiency result primarily from a reduction in thermoregulatory non-shivering thermogenesis, and this has been dernonstrated by metabolic rate measurements and pair-feeding studies conducted at different environmental temperatures (Trayhurn \& James, 1978; Thurlby \& Trayhurn, I979; Trayhurn, 1979; Trayhurn \& Fuller, 1980).

Purine nucleotide binding studies have shown that thermogenesis in BAT is depressed in the $o b / o b$ mouse, and that unlike lean animals, it could not be increased during acute exposure to cold (Himms-Hagen \& Desautels, 1978). Long-term adaptations in BAT of $o b / o b$ mice do, however, occur (Hogan \& Himms-Hagen, 1980). Scatchard analysis of binding data has indicated that the reduced purine nucleotide binding to $\mathrm{BAT}$ mitochondria of $o b / o b$ mice is due to a reduction in the amount of the 32000 molecular weight 'uncoupling' protein, and not to any changes in affinity (Goodbody \& Trayhurn, 1981). Additional in vitro techniques for assessing the thermogenic activity of $\mathrm{BAT}$ of lean and $a b / a b$ mice 
have been employed, including mitochondrial $\mathrm{Ca}^{2+}$ influx measurements (Fraser \& Trayhurn, 198I) and measurements of mitochondrial membrane potential and respiration rate (A. E. Goodbody, D. R. Fraser and P. Trayhurn, unpublished results) and all have yielded results which are consistent with lower heat production in the obese.

The quantitive importance of BAT in the reduced thermogenesis of $o b / o b$ mice has been determined directly by measurements of regional blood flow together with in vivo measurements of tissue oxygen utilization, and almost all $(93 \%)$ of the difference in non-shivering thermogenesis between lean and obese mice appears to be attributable to BAT (Thurlby \& Trayhurn, I 980 ).

Purine nucleotide binding studies have also been performed with BAT from the diabetic-obese mouse and similar results to those found with the $a b / o b$ mutant have been obtained (Goodbody \& Trayhurn, 198I). In both mutants decreased thermogenesis in BAT is evident by $\mathrm{rO}^{-} \mathrm{I}_{4} \mathrm{~d}$ of age (Goodbody \& Trayhurn, $\mathrm{I} 98 \mathrm{I}$ ), and this is the age at which an excessive amount of fat begins to be deposited. A reduction in energy expenditure on non-shivering thermogenesis in BAT may therefore be the primary factor initiating the development of obesity in at least two different obese mutants.

\section{Cafeteria-fed rats}

Several studies have shown that when rats are given access to a varied and highly palatable 'cafeteria' diet substantial voluntary overeating takes place (Sclafani \& Springer, I976; Rothwell \& Stock, I979a,b; Rolls et al. I980; Stephens, I 980 ). In some cafeteria feeding experiments evidence for the occurrence of substantial dietary-induced thermogenesis has been obtained, and this dietary thermogenesis serves to minimize the extent to which the excess dietary energy is retained by the animal (Rothwell \& Stock, 1979a).

A number of observations have now been made which indicate that dietary-induced thermogenesis is generally similar to non-shivering thermogenesis (Rothwell \& Stock, 1980), and that the energy dissipative, or regulatory, component of the process also takes place in BAT. BAT hypertrophies in those rats which demonstrate high dietary-induced thermogenesis on cafeteria feeding, and this hypertrophy is not simply the result of an increase in the amount of triacylglycerol in the tissue (Rothwell \& Stock 1979a). In addition to an increase in the protein content in interscapular BAT of cafeteria-fed rats, substantial increases in the total activity of both cytochrome oxidase and $\alpha$-glycerophosphate dehydrogenase have been observed (Brooks et al. I980); these increases in enzyme activity are indicative of an increase in the over-all oxidative capacity of the tissue. Other changes noted in BAT of cafeteria-fed rats include an increase in vitro in the lipolytic response to nor-adrenaline (Rothwell \& Stock, 1979a) and an increase in the activity of the $\mathrm{Na}^{+}-\mathrm{K}^{+}$ATPase (Rothwell et al. $\mathrm{I} 98 \mathrm{I}$ ). Purine nucleotide binding studies indicate that the proton conductance pathway in BAT mitochondria is increased in cafeteria-fed rats, although the increase is less than that found in cold-adapted animals (Brooks et al. 1980). Similar observations have 
also been made on mice fed a cafeteria diet (A. E. Goodbody and P. Trayhurn, unpublished results).

All these changes in BAT of rats exhibiting substantial dietary-induced thermogenesis during cafeteria feeding are consistent with increased thermogenesis in the tissue. The quantitative importance of BAT to dietary-induced thermogenesis in cafeteria-fed rats has been demonstrated by blood flow measurements with microspheres, together with measurements of tissue oxygen utilization in vivo (Rothwell \& Stock, 198I). It is important to emphasize that since one of the effects of overeating in rats would be to decrease the requirement for thermoregulatory thermogenesis, it is difficult to interpret the changes in BAT of cafeteria-fed rats as being other than part of a regulatory, energy-dissipating mechanism - even if the quantitative contribution of such a mechanism remains controversial, and there are marked differences between animals of different strains and different ages.

\section{Ventromedial hypothalamic lesions}

There are several reports which indicate that lesions of the ventromedial hypothalamus do not result merely in hyperphagia, but that a more 'efficient' animal is produced since there is increased energy retention on a normal energy intake. Lesioning the ventromedial hypothalamus in rats has now been shown to result in decreased fatty acid oxidation in BAT, and this appears to be due to a 'functional disconnection' of the tissue (Seydoux et al. 198I). Preliminary studies also indicate that the depletion of hypothalamic nor-adrenaline leads to a reduction in purine nucleotide binding to BAT mitochondria (B. J. Sahakian and P. Trayhurn, unpublished results). Both of these observations indicate a reduction in BAT thermogenesis in lesioned animals.

\section{Conclusions}

There is now much evidence to indicate that reduced thermogenesis in BAT plays a key role in the ability of genetically obese mice $(o b / o b$ and $d b / d b)$ to become obese on a 'normal' energy intake. Conversely, there is increasing evidence that the ability of certain strains of rat to minimize the development of obesity in the face of a high energy intake results from the stimulation of BAT thermogenesis. The current emphasis on BAT as the main effector of non-shivering and dietary thermogenesis stems from the discovery of the quantitative importance of this tissue to the total thermogenesis of small adult rodents. There is considerable doubt, however, as to the universality of the 'brown fat hypothesis', for not only do some mammals appear to have no BAT, but the mere presence of the tissue does not necessarily signify that it is functionally active (Brockway \& Lobley, I98I). In a number of circumstances it is necessary, therefore, to continue to explore thermogenic mechanisms in tissues other than BAT, and dietary-induced thermogenesis in pigs fed on low-protein diets may represent just such a circumstance (Miller \& Payne, I962; Gurr et al. 1980). Finally, substantiating the view that there is an important role for BAT in the aetiology of human obesity is a 
major task, not least because the quantitative importance of reduced thermogenesis itself in determining obesity in man has not been convincingly documented.

A. E. G. acknowledges the receipt of a studentship from the Medical Research Council.

\section{REFERENCES}

Brockway, J. M. \& Lobley, G. E. (1981). F. Physiol., Lond. 314, 85.

Brooks, S. L., Rothwell, N. J., Stock, M. J., Goodbody, A. E. \& Trayhurn, P. (1980). Nature, Lond. 286, 274 .

Contaldo, F., Gerber, H., Coward, W. A. \& Trayhurn, P. (198I). In Obesity: Pathogenesis and Treatment, p. 319 [G. Enzi, G. Crepaldi, G. Pozza and A. E. Renold, editors]. London and New York: Academic Press.

Foster, D. O. \& Frydman, M. L. (1978). Can. F. Physiol. Pharmacol. 56, i10.

Foster, D. O. \& Frydman, M. L. (1979). Can. F. Physiol. Pharmacol. 57, 257.

Fraser, D. R. \& Trayhurn, P. (1981). Biochem. Soc. Trans. 9, 470.

Goodbody, A. E. \& Trayhurn, P. (1981). Biochem. F. 194, I019.

Gurr, M. I., Mawson, R., Rothwell, N. J. \& Stock, M. J. (I980). F. Nutr. r 10, 532.

Heaton, G. M., Wagenvoord, R. J., Kemp, A. \& Nicholls, D. G. (I978). Eur. F. Biochem. 82, $5^{1} 5$.

Himms-Hagen, J. \& Desautels, M. (1978). Biochem. Biophys. Res. Commun. 83, 628.

Hogan, S. \& Himms-Hagen, J. (1 980). Am. f. Physiol. 239, E301.

Horwitz, B. A. (1978). In Strategies in the Cold: Natural Torpidity and Thermogenesis, p. 6I9 [L. C. H. Wang and J. W. Hudson, editors]. London and New York: Academic Press.

Jansky, L. (I973). Biol. Rev. 48, 85 .

Lin, P.-Y., Romsos, D. R. \& Leveille, G. A. (1977). 7. Nutr. 107, I7 5.

Miller, D. S. \& Payne, P. R. (1962). F. Nutr. 78, 255.

Nicholls, D. G. (1976). Eur. F. Biochem. 62, 223.

Nicholls, D. G. (1979). Biochim. Biophys. Acta 549, I.

Rath, E. A. \& Thenen, S. W. (1979). F. Nutr. 109, 840.

Rolls, B. J., Rowe, E. A. \& Turner, R. C. (1980). F. Physiol., Lond. 298, 415.

Rothwell, N. J. \& Stock, M. J. (I 979a). Nature, Lond. 281, 3 I.

Rothwell, N. J. \& Stock, M. J. (1979b). F. Comp. Physiol. Psychol. 93, 1024.

Rothwell, N. J. \& Stock, M. J. (I980). Can. F. Physiol. Pharmacol. 58, 842 .

Rothwell, N. J. \& Stock, M. J. (I98I). Pflügers Arch. 389, 237.

Rothwell, N. J., Stock, M. J. \& Wyllie, M. G. (1981). Biochem. Pharmacol. 30, 1709.

Sclafani, A. \& Springer, D. (1976). Physiol. Behav. 1 7, 461.

Seydoux, J., Rohner-Jeanrenaud, F., Assimacopoulos-Jeannet, F., Jeanrenaud, B. \& Girardier, L. ( I981). Pflügers Arch. 390, I.

Stephens, D. N. ( 1980$)$. Br. F. Nutr. 44, 2 I 5.

Thurlby, P. L. \& Trayhurn, P. (1979). Br. F. Nutr. 42, 377 .

Thurlby, P. L. \& Trayhurn, P. (1980). Pflügers Arch. 385, I93.

Trayhurn, P. (1 979). Pflügers Arch. 380, 227.

Trayhurn, P. (1 8 I). Biochim. Biophys. Acta 664, 549.

Trayhurn, P. \& Fuller, L. (I980). Diabetologia 19, 148.

Trayhurn, P. \& James, W. P. T. (1978). Pflügers Arch. 373, 189. 